\title{
Gazette
}

\section{Minutes of April 2017, APSA Council Meeting}

\author{
Saturday, April 8, 2017 \\ Chicago, IL - The University of Chicago \\ Booth School of Business Gleacher \\ Center
}

\section{MEMBERS PRESENT}

President: David Lake; President-Elect: Kathleen Thelen; Vice President: Janet BoxSteffensmeier; Vice President: Ian Shapiro; and Treasurer: Taeku Lee

Council Members: Mark Crescenzi, Roxanne Euben, Juliet Hooker, Amaney Jamal, Brett Ashley Leeds, James Mahoney, Colleen Shogan, Caroline Tolbert, Renée Van Vechten, and Christina Wolbrecht

Guest: Past-President: Jennifer Hochschild

APSA Staff: Steven Rathgeb Smith, Kara Abramson, Betsy Super, Kimberley Mealy, Patrick French, Dan Gibson, Meghan McConaughey, Teka Miller, Ashley Vande Bunte, and Barbara Walthall

Not in Attendance:Vice President: Elaine Kamarck; Secretary: Marion Orr; Matt Barreto, Omar Encarnación, Kristian Gleditsch, Jeffrey Isaac, Byron D’Andra Orey, Bo Rothstein, and Cameron Thies

\section{CALL TO ORDER}

APSA President David Lake called the meeting to order on April 8, 2017 at 8:30 a.m.

\section{CONSENT AGENDA}

Fall 2016 Council Meeting minutes and PS Editorial Board nominees are introduced as part of the consent agenda. There are no questions or corrections to the minutes. T. Lee moves to approve the Fall 2016 Council Meeting minutes, motion is seconded and approved unanimously. President Lake then moves to approve the proposed PS Editorial Board nominees, motion is seconded and approved unanimously.

\section{PRESIDENT'S REPORT}

Lake introduces the president's report to update the council on current issues facing the association. Lake discusses the work being done around implementing the newly passed APSA bylaws, as well as ongoing work to advance the APSA publications portfolio. He also updates the council on the work of the research ethics committees comprising Lake's presidential task force, on human subjects research and on conflicts of interest.

\section{TREASURER'S REPORT}

Treasurer T. Lee introduces the treasurer's report to update the council on the association's financial position. T. Lee reports that APSA continues in sound financial shape. The association's independent audit was performed by a new auditing firm, Rubino \& Company. The firm has reported that a clean audit was conducted and confirmed by Tolbert, chair of the Audit committee. The association has $\$ 34.5$ million in investments; $\$ 15.8$ million in the trust and development portfolio; $\$ 15.8$ million in the CFP trust portfolio, and is projecting revenue of $\$ 2.278$ million from operations.

\section{EXECUTIVE DIRECTOR'S REPORT}

Executive Director Steven Rathgeb Smith provides an update on the status of the APSA journals, APSA's advocacy efforts, diversity and inclusion initiatives, and planned updates to APSA connect. Shogan asks for more details regarding the strategy for APSA's lobbying efforts. Abramson discusses the details of APSA's congressional outreach and the focus on partnering with COSSA and similar organizations in these efforts. Hochschild, Mahoney, Box-Steffensmeier, Tolbert and T. Lee all express support for expansion and innovation in diversity and inclusion efforts. Super and Mealy note that the RBSI Advisory Committee is working to identify options for new and expanded diversity and inclusion efforts.

\section{BOARD POLICY MANUAL}

Lake introduces the proposed Board Policy Manual policies for council consideration and approval. Lake explains the background of the board policy manual and what prompted the creation of this document. These policies have been developed to support and clarify the implementation of the newly-adopted APSA bylaws. These changes ensure that APSA's policies are in compliance with the new bylaws. Lake details the policies to be voted on today and which policies the council will have presented to them in August.
Van Vechten moves to approve the revised election process policy, the motion is seconded and approved unanimously. Mahoney moves to approve the updated process for nominations by petition, the motion is seconded and approved unanimously. Discussion turns to the rules for the Annual Business Meeting. Thelen asks why the quorum for the business meeting is $1 \%$ of membership. Lake explains the discussion that led to the decision and notes that this is a provision in the bylaws. The new bylaws now include additional means for bringing issues to the council and the membership outside of the business meeting. Tolbert moves to approve the new rules for the Annual Business Meeting, the motion is seconded and approved unanimously. Crescenzi moves to approve the rest of the policy manual, the motion is seconded and approved unanimously.

\section{TEACHING AND LEARNING CONFERENCE}

Smith introduces discussion of the APSA Teaching \& Learning Conference (TLC) for the purpose of council discussion and approval of a new plan for the TLC. Smith discusses TLC's background and the efforts of the TLC review committee, the APSA staff and the Teaching and Learning policy committee and introduces the memo outlining options for the TLC. The options have been discussed and reviewed by the Teaching and Learning Policy Committee. The policy committee chair, Van Vechten, introduces the committee's thoughts on the memo. The committee recognizes that challenges that the current TLC format poses, including relatively high per-capita cost and high use of staff time. Van Vechten presents the committee's recommendations to: 1) move to a biennial format for TLC, with off-year mini-conferences coordinated with the annual meeting; 2) move away from the track format to a hybrid format by retaining popular tracks but also providing independent panels and workshops unrelated to the tracks; 3) work with the Political Science Education Organized Section and possibly local colleges to support the planned mini-conferences. Mahoney, Hochschild, Van Vechten, Thelen, and Tolbert discuss the various options and provide 
additional suggestions for moving forward. Van Vechten moves to shift the Teaching and Learning Conference to a biennial format, with off-year mini-conferences in coordination with APSA. The motion is seconded and approved unanimously. Van Vechten moves to shift the format of TLC to a hybrid track format. The motion is seconded and approved unanimously. Van Vechten moves to consider eliminating the Teaching and Learning Division and combining it with the Political Science Education Section. The motion is seconded and approved unanimously. Lake moves to sunset Teaching and Learning standing committee, the motion is seconded, and approved unanimously.

\section{CONFLICT OF INTEREST}

\section{COMMITTEE}

Lake introduces discussion of the proposed committee on conflicts of interest for the purpose of council discussion and approval. Lake gives background and rationale for the creation of the committee, noting that APSA is one of very few professional associations without an official financial conflict of interest policy and he hopes to be able to address this during his time as APSA president. Lake opens discussion on the committee charge and membership. Thelen moves to approve the committee, a motion is made and seconded, discussion follows. Crescenzi, Shogan, Lake, and Tolbert discuss the implications a financial conflict of interest policy would have. Shapiro offers another motion to approve the committee charge and membership, motion is seconded, and approved unanimously.

\section{TECHNOLOGY TASKFORCE}

Hochschild introduces discussion of her presidential taskforce on technology for the purpose of updating the council. The taskforce has had several meetings collectively and in focused sub-groups and has met with APSA staff regarding implementing some of the recommendations. The taskforce will be producing a report, including additional recommendations, which will be available online through $P S$.

\section{ANTI-HARASSMENT POLICY}

Lake introduces the proposed anti-harassment policy for the purpose of council discussion and approval. Lake gives background on APSA's anti-harassment efforts including the policy developed by the Ethics Committee, which had created an ombuds position to address harassment concerns. The council had approved this proposal but also had concerns that there was no clear proce- dure for implementing the anti-harassment policy. Euben provides background on the work that the ad hoc committee on sexual harassment has done since the last council meeting on developing implementation procedures for the anti-harassment policy. The committee has created a proposed policy for addressing harassment complaints as well as a supporting memo with additional considerations moving forward. Van Vechten, Euben, and Super discuss issues of whether home institutions should ever be informed of harassment complaints. Euben, Jamal, and $\mathrm{T}$. Lee note that this is an important question, but is outside of the committee's mandate and could expose the association to liability. Leeds and Hochschild express concern about the anonymity of complaints and the possibility of retaliation. The ad hoc committee agrees that retaliation is a concern and more explicit language on that may be helpful to include. Issues of anonymity are also important, but anonymity cannot be guaranteed. Thelen and Shapiro emphasize that because APSA does not have control over bystanders or other participants in a concerning interaction the policy should be clear not to guarantee anonymity. Shogan, Hochschild, Thelen and Tolbert note the importance of education and training in the overall antiharassment strategy. Shogan asks what will happen if a harasser is reported several times consecutively. T. Lee notes that while there is no way for APSA to increase sanctions for multiple informal reports there will always be the specter of the formal process for repeat offenders. Wolbrecht, Jamal, and Super discuss the bounds of the policy and who is covered. For example, is online harassment covered by the policy? Super clarifies that the definition of "on-site" turns on people who are registered attendees during the period of the meeting, so online harassment by a registered attendee could be covered under the policy. The committee notes that many of these are important questions, but some of the details will need to be worked out in practice. Super, Wolbrecht, Hochschild, and Euben discuss the sexual harassment survey being conducted by the Professional Ethics, Rights and Freedoms Committee, and how those survey results will inform future policies. The committee consults and proposes that they make changes to the policy and will present the edited policy for a vote once those changes are completed.

\section{ADVOCACY GUIDELINES}

Smith introduces discussion of the proposed advocacy guidelines for the purpose of coun- cil discussion and approval. He highlights that the proposal encompasses council feedback since 2015 and ensures compliance with the new bylaws. Abramson highlights some key portions of the document for the council, and explains the types of advocacy that these guidelines would allow. Smith and Abramson discuss which situations would or would not be covered by this policy. Mahoney moves to approve the advocacy guidelines, the motion is seconded and approved unanimously.

\section{JOURNAL DATA COLLECTION}

Lake introduces the Publications Policy Committee memo on journal data collection, for council discussion and approval. Leeds gives an overview of the memo and the goals of the journal data collection policy, including addressing and identifying issues of representation and bias in the review process and considering editor time and resources. The council discusses issues of privacy, data validity, data entry procedures, and editor autonomy. Lake clarifies that the council is being asked to vote on the overall approach, and the committee will continue to work out the details. Lake moves to approve the proposed journal data collection policy, the motion is seconded and approved unanimously.

\section{OPEN ACCESS JOURNALS}

Lake introduces discussion of the open access journal proposal for council discussion and decision. Lake begins the discussion by going over the proposals that have been received and the process the search committee has taken to review them. Leeds discusses the publications policy committees' recommendation not to approve the proposed editorial team. Motion is made to not appoint the proposed editorial team, the motion is seconded and approved unanimously. Smith provides background on the proposed open access journal generally. Lake, Van Vechten, Tolbert, and Smith discuss the journal's financial plan and overall goal. The council reaches a consensus that the APSA staff and publications committee will reconsider the purpose and plan for the open access journal and return to the subject at a later date.

\section{ANTI-HARASSMENT POLICY FOLLOW-UP}

Euben provides the council with an updated version of the proposed anti-harassment policy. Lake asks for comments to the changes language, and there are none. Van Vechten moves to approve the updated anti-harassment policy, the motion is seconded and approved unanimously. 


\section{PS EDITOR REVIEW COMMITTEE}

Smith introduces discussion of the PS editorial review for the purpose of council approval for the appointment of a review committee. Smith provides background on the editor review process the history of the $P S$ editors. Leeds, Lake, Crescenzi, and Walthall discuss the editors' term length. Leeds moves to create a $P S$ editors review committee, the motion is seconded and approved unanimously.

\section{RESEARCH OVERSIGHT COMMITTEE}

Super introduces the proposed creation of a research oversight committee for the purpose of council discussion and approval. Super describes the history and accomplishments of the research department and explains the purpose of the research oversight committee. Lake, Jamal, Hochschild, and Super discuss the committee makeup, and Thelen emphasizes the importance of staggered terms. Lake makes a motion to approve the creation of the research oversight committee, the motion is seconded and approved unanimously.

\section{RALPH BUNCHE SUMMER INSTITUTE (RBSI)}

Mealy introduces discussion of the RBSIAdvisory Committee for the purpose of discussion and providing an update. Mealy describes the history of the RBSIAdvisory Committee, and their discussion of current programming and funding as well as future work. The council discusses how the committee's work can best be supported. Mealy notes that the RBSIAdvisory Committee will be presenting recommendations to strengthen, and possibly expand, the program to the council in the future.

\section{POLICY UPDATES}

Council policy committee chairs offer updates on the work of their committees.
Shapiro notes that the Meetings and Conferences Committee will work to update the siting policy and consider the annual meeting's purpose. Van Vechten explains that the Teaching and Learning Policy Committee will work to expand the teaching and learning resources available from APSA. Shogan notes that the Membership and Professional Development Policy Committee will work on a plan for increasing retention and targeting large portions of the membership. Leeds explains that the Publications Policy Committee will work on rethinking journal structure and data collection.

\section{NEW BUSINESS}

Van Vechten introduces discussion of the APSA website content and requests more emphasis on teaching and learning on the main screen of the website. 